\title{
COVID-19 Pandemic Planning and Preparedness for Institutions Serving People Living With Disabilities in South Africa: An Opportunity For Continued Service and Food Security
}

\author{
Loraine Boitumelo (LB) Mzini
}

\begin{abstract}
Department of Public Administration, School of Government Studies, School of Government Studies, NorthWest University, P O Box 1174 Vanderbijlpark 1900, South Africa
\end{abstract}

\begin{abstract}
On March 11, 2020, the World Health Organization declared the COVID-19 outbreak as pandemic just about three months after its emergence in December 2019 in Wuhan, China. The outbreak of COVID-19 launched the world into a public health crisis, impacting families, schools, and communities in unprecedented ways. This paper examines the existence of pandemic planning and preparedness for institutions serving PLWD in order to ensure continued service for its users. The research also analyses the considerations applied to address the challenges that a pandemic will present. This study comes at an opportune moment when institutions serving PLWD become overwhelmed and face possible closure of their facilities. As COVID-19 continues to have wide-reaching impacts across the globe, it is important to understand how persons with disabilities are uniquely impacted by the pandemic, including health, education, and food security.
\end{abstract}

Method: A qualitative study was considered complemented by telephone interviews in two facilities (Evaton and Katlehong) serving PLWD were used as a case study.

Results: The paper concludes that adequate pandemic planning and preparedness in response to COVID-19 are critical to saving both lives and livelihoods and continuous service delivery. The respondents articulated a need for inclusive strategies where disabled people are involved as consultants and partners, not just as users.

Conclusion: Diligent planning was found to be essential. The results highlight the role of the institutions serving PLWD in being effective and supporting service delivery and food security.

Keywords: COVID-19, people living with a disability, pandemic planning, preparedness, food security, South Africa.

\section{INTRODUCTION}

On March 11, 2020, the World Health Organization declared the COVID-19 outbreak as pandemic just about three months after its emergence in December 2019 in Wuhan, China. The speed and scale of transmission of the COVID-19 pandemic are now a health and humanitarian crisis threatening the food security and nutrition of millions of people around the world. Hundreds of millions of people were already suffering from hunger and malnutrition before the virus hit. The outbreak developed into a global economic crisis with an anticipated shortfall in global income.

The coronavirus pandemic is accelerating in Africa and caused unprecedented societal and economic disruptions. As of June 30, 2020, the cumulative number of confirmed COVID-19 cases in South Africa was 151 209, with 6945 new cases reported. As the COVID-19 pandemic continues to spread globally, schools are closed in 180 countries, leaving an estimated 1.5 billion children out of school. COVID-19 presents a significant and unprecedented challenge for

*Address correspondence to this author at the Department of Public Administration, School of Government Studies, School of Government Studies, North-West University, P O Box 1174 Vanderbijlpark 1900, South Africa; Tel: +27 16910 3462; Fax: +27 16910 3449; E-mail: Tumi.Mzini@nwu.ac.za, tumi.mzini@gmail.com many people living with disabilities (PLWD). Disability is understood as an evolving concept that results from the interaction between persons with impairments and attitudinal and environmental barriers in society. There are more than 1 billion PLWD worldwide. Some PLWD is more likely to be vulnerable to the effects associated with COVID-19 putting them at risk of increased morbidity and mortality. Amidst the current pandemic, people with disabilities also experienced high discrimination levels, lack of access to essential services, social exclusion, and poverty. It is difficult to predict how long school closures will last, so the most vulnerable children's health, food security, and nutrition must be prioritised. This crisis calls on the rapid development and implementation of alternative methods to contain the COVID-19 outbreak, especially to PLWD. School divisions and schools have emergency plans for several crises but have not generally planned a community-wide health emergency such as a COVID-19 pandemic. The World Bank is keen to leverage this opportunity to make learning more inclusive for children with disabilities now and in the future.

There is a call for institutions to review their plans and consider what actions can be taken to enhance preparedness and minimise the potential adverse 
effects of the spread of COVID-19 [1]. Piatta [2] explored the "Social Model of Disability". The Social Model of Disability is regarded as an empowering concept that allows people with disabilities to become key agents for development and challenge the root causes of exclusion [2]. Quarmby and Pillay [3] explored and described the knowledge and experience of humanitarian aid workers and health care professionals in food assistance contexts about the nutrition and food security of people living with disabilities. Hiranandani [4] assessed processes for enhancing equity for people with disabilities and changing society's attitudes to end the povertydisability cycle and to improve food and human security.

Service institutions play an important role in protecting children's health and safety and their families and staff. As COVID-19 continues to have wide-reaching impacts across the globe, it is important to understand how persons with disabilities are uniquely impacted by the pandemic, including health, education, and food security. It is difficult to predict how long school closures will last, so the health, food security, and nutrition of the most vulnerable children must be prioritised. In this paper, the author reflects on what is happening to PLWD in the African continent with reference to the selected institutions of Gauteng province. The author explores the role of pandemic planning and its existence in institutions serving PLWD in order to ensure continued service for its users. The research also analyses the considerations applied to address the challenges that a pandemic will present.

This article is organised into three sections. Section One presents the context of pandemic and COVID-1. It provides background on the nature of the COVID-19 pandemic, its general effects and management, and preparations for coordinating a response. Section Two presents the results of the survey undertaken during the COVID-19 pandemic. Section Three describes the preparedness process planning, including the major impacts that schools will face and suggestions for dealing with them. It provides a brief conclusion about maintaining the plan and training.

\section{CONCEPTUALISING PANDEMIC}

Throughout the course of history, disease outbreaks have ravaged humanity, sometimes changing the course of history and, at times, signalling the end of entire civilisations [5]. The likelihood of new diseases quickly spreading has grown with increased travel and mobility. The word "pandemic" comes from the Greek "pandemos," meaning pertaining to all people. Pandemics are usually caused by an infectious agent that is newly capable of spreading rapidly. A pandemic is a term used in public health to describe an epidemic that crosses international boundaries and impacts a large number of people. A pandemic is the global outbreak of a disease. A pandemic is not your normal business disruption. Unlike a cyberattack or natural disaster, it can affect operations globally for months and threatens the workforce directly [6]. A pandemic is a significant leveller in that no person and no nation remains impervious, even if not all are equally at risk or impacted [7]. A pandemic occurs when three conditions have been met:

- A new influenza virus subtype emerges.

- It infects humans, causing serious illness.

- It spreads easily and sustainably among humans [8].

A global pandemic has been a looming risk for decades-more than 20 worst epidemics and pandemics, dating from prehistoric to modern times. One of the greatest and most likely threats to the public's health is naturally occurring pandemics [8]. Global pandemics have been reported for many hundreds of years. In 1889-1890 the Flu pandemic occurred and was reported in Russia as a new transport link was introduced and claimed almost 1 million people throughout the world [5]. The bestdocumented pandemics occurred in 1918 (H1N1, the Spanish flu), 1957 (H2N2, the Asian flu), and 1968 (H3N2, the Hong Kong flu) [9]. In 1981 to-date the AIDS was a pandemic by the late 20th century and has claimed an estimated 35 million lives since it was first identified. For decades, the disease had no known cure, but medication developed in the 1990s, which now allows people with the disease to experience a normal life span with regular treatment [5].

Between the spring of 2009 and the spring of 2010, the virus-infected as many as 1.4 billion people across the globe and killed between 151,700 and 575,400 people. It's been a little over a decade since the world experienced its last pandemic. Now, the world is in the midst of the COVID-19 pandemic caused by a novel coronavirus called SARS-CoV-2 [8]. COVID-19 has come as a shock to society, health systems, economies, and governments worldwide [9]. Since the outbreak, COVID-19 has spread to over 200 countries and territories globally [11]. 


\section{Persons with Disabilities}

Persons with disabilities are one of the largest minority groups in the world. According to estimates commonly used by international bodies, people with disabilities comprise $10 \%$ of the world's population, with $85 \%$ living in developing countries [12]. Article 1 of the UN Convention on the Rights of Persons with Disabilities defines persons with disabilities as "the persons who have long-term physical, mental, intellectual or sensory impairments which in interaction with various barriers may hinder their full and effective participation in society on an equal basis with others" [13].

Three out of five persons with disabilities are women, and disability is more common among children and adults who are poor [13]. People with disabilities normally face enormous challenges, including food security [14]. Many of them are consistently left out of development gains [15]. Disability remains an underrepresented topic in food security policy and practice. Disability can be understood as both a cause and a consequence of poverty resulting from ignorance, low expectations, prejudice, and lack of opportunities [16]. The intersectionality between disability and nutrition may best be understood through a food security framework [3]. The 1996 World Food Summit defined that Food security exists "when all people, at all times, have physical and economic access to sufficient safe and nutritious food that meets their dietary needs and food preferences for an active and healthy life" [17]. People with disabilities comprise one in five of the global population living below the poverty line [2].

Disability is a multi-dimensional and human rights issue, like gender, ethnicity, and culture. An important priority for disability policy is the capacity-building of disabled people's organisations [16]. Persons with disabilities face challenges in fully participating in a society, which is further heightened by discriminatory social attitudes; this culminates in marginalisation and significant barriers to their inclusion and participation in society and development [13]. There have been some steps forward to ensure people with disabilities benefit from plans to meet the MDGs. The African Union and the European Union have developed action points on disability in the health and education sectors of the MDGs, as part of a joint document presenting their strategy and 2008-2009 action plan for Africa. The UN Convention on the Rights of People with Disabilities (CRPD) is the first human rights instrument specific to people with disabilities and promotes their full participation in economic, social, cultural, and political life. The CRPD provides the framework for international agencies, donors, and partner governments to build on their existing commitments in the area of disability and development line [2]. The Convention also addresses other crosscutting issues such as:

- the participation of people with disabilities and their representative organisations;

- $\quad$ mainstreaming, i.e. the inclusion of disability in all development activities and at all stages; and

- $\quad$ support at the community level, which means the availability of adequate services and resources to enable people with disabilities to live autonomously in their local community [2].

In terms of being left out of development processes and development progress, the UNDP is committed to an inclusive approach to sustainable human development, which benefits all and ensures that no one is left behind [13]. The Convention represents an important step in changing the perception of disability, in making society understand that people with disabilities are full citizens who are entitled to the same rights as everyone else [2]. It sets out rights but also binding principles for its application [2]. The UNDP also undertakes disability-inclusive development by supporting countries to develop and strengthen disability law and policy frameworks and promote the participation of PLWDs in political and public life [15].

\section{Pandemic Planning}

A number of assumptions, based on previous pandemics and medical research, have been made for planning purposes [18]. It is a continuous process of planning, and it unfolds over months. Pandemic preparedness is most effective if it is built on general principles that guide preparedness planning for any acute threat to public health. A key component of pandemic planning is the incorporation of policies for the resumption of normal business activities once virus containment measures have been eased. The process comprises various activities, including strategic planning, operational planning, exercises and reviews, implementation, and evaluation. In terms of exercises and reviews, countries must all have the capacity to access and interpret data for risk assessment provided. Every organisation must plan for the specific disruptions it may face during an influenza pandemic. The objective of pandemic planning is to:

- $\quad$ describe countries' strategies for responding to a pandemic supported by operational plans at national and sub-national levels. 
- $\quad$ enable countries to be prepared for recognising and managing a pandemic [9];

- $\quad$ reduce illness (morbidity), death (mortality), and social disruption resulting from an influenza pandemic;

- $\quad$ reduce transmission of the pandemic virus strain and mortality rates. In the health sector, pandemic planning is executed to ensure that essential services are continuously provided. It also ensures that health care providers or resources to meet the increased demand for health services are in encourages organisations to start incorporating new practices in their dayto-day operations that will help them during a pandemic or any other emergency;

- lays out issues of special concern for service agencies on pandemic preparation and response, and offers initial guidance;

- It identifies areas for future discussion and planning and encourages organisations to incorporate new practices in their day-to-day operations to help during the pandemic or any other emergency place $[9,19,20]$.

\section{COVID-19 PANDEMIC'S IMPACT ON PLWDS}

Lessons from past epidemics on disability inclusion are limited. This section provides some general background on an influenza pandemic and its potential effects. A pandemic virus may adversely affect different age groups. For instance, in the 1918-19 pandemic, 20 to 50-year-olds were most severely affected [18]. The outbreak of COVID-19 launched the globe into a public health crisis, impacting families, schools, and communities in unprecedented ways. Disability in development remains stuck in the 'special needs' section of targeted projects on health, education, and welfare [21]. Reports from the media, disability advocates, and disabled peoples' organisations (DPOs) point to several emerging impacts, including primary and secondary impacts [22].

\section{Primary Impacts of COVID-19 on People with Disabilities}

The two primary impacts of COVID-19 are presented in the following sections.

\section{Attitudinal, Environmental, and Institutional Barriers}

People with disabilities may be at greater risk of contracting COVID-19 for several reasons. In Kenya, media has reported that people with albinism are experiencing increased discrimination and abuse during the pandemic and falsely associating people with albinism with COVID-19 [23]. This could be caused by attitudinal, environmental, and institutional barriers that form part of the COVID-19 response [22]. Increased risk of stigma, discrimination, neglect, violence, and abuse is also identified as an impact [22].

\section{Higher Risk of Serious Illness}

The world of service for PLWD is often fraught with barriers. People with disability live and work in a range of settings may increase the risk of morbidity and mortality. COVID-19 also contributes to the rise of underlying health conditions and disabilities, which can deter their health. People with disabilities experience higher morbidity rates, which includes managing additional health concerns such as mental health conditions, chronic conditions, and complex comorbidities [24]. COVID-19 may increase the prevalence of mental health conditions and worsen preexisting psychosocial disabilities. Increased stress from the actual pandemic will also increase the mental health service needs throughout the schools and community. The epidemic may also expose higher levels of stress and may interrupt access to essential services.

\section{Secondary Impacts of COVID-19 on People with Disabilities}

Secondary impacts of the response to the pandemic may include health, education, food security, and livelihood challenges [22].

\section{Reduced Access to Essential and Routine Health Services}

There are also a number of barriers that people with disability face when accessing health care [24]. Measures to contain the spread of COVID-19 include strong restrictions of movement that dramatically change daily lives and impact PLWD [25]. Some carry out their daily activities with the help of personal assistants are more affected, and social distancing makes it hard for receiving the help needed. Parents of children with disabilities have no guidance on how to provide assistance to their children during COVID-19, especially now that the services of personal assistants are not available, even though schools are closed. Moreover, "there are no accessibility measures in place for children with disabilities to continue their education remotely" [26]. 


\section{Impact on Schools}

Nearly 1.5 billion children of the student population are being kept away from school due to pandemic response measures [27]. COVID-19 spreads rapidly in schools, especially in winter, and it is expected to occur even more quickly. Many persons with disabilities do not have access to information related to health recommendations. Information in braille, sign language, easy to read is unavailable, and websites are inaccessible. Another issue to communication is language barriers, as there are no translated materials into local languages. Many are unable to understand English, meaning the information they can access is limited [26]. Schools may also be affected by disruptions to transportation services, especially when most low-income households depend on public transportation.

\section{Impact on Business}

A pandemic will also affect businesses, with staff getting sick and staying home. There is too many and disproportionate unemployment of people with disabilities. This, in turn, has resulted in large shortterm economic losses and a decline in global economic activity not seen since the Great Depression [11]. There is a risk that the world could be yet more divided, conflictual, and nationalistic. Governments may face gigantic debts, while many households and businesses were already heavily indebted before the crisis [28].

\section{Food Security}

Pandemics are likely to have a potential disruption of local food systems. It can further restrict children's access to adequate food and diet quality. It also impacted school feeding programmes as schools are closed. Fluctuating food prices also impacts especially households who want to ensure that children have access to nutritious school meals and nutrition services.

\section{Impact on Employee Absenteeism}

A pandemic outbreak could also jeopardise essential community services by causing high absenteeism levels in critical positions in every workforce. The Centers for Disease Control and Prevention [29] estimates that " 15 to $35 \%$ of the population will become ill during the course of a pandemic". The resulting high rates of employee absenteeism will affect every sector and probably every homeless service agency. Many people who are not ill may stay home to care for children, other family members who are ill. Some people may stay home due to concerns or fears about potential exposure to the virus in the community and the workplace. The resulting high employee absenteeism rates will affect every sector, and probably every homeless service agency [20].

During this uncertain time, PLWD needs have to be addressed, including the accessibility of online learning options and nutrition. Unlike natural disasters, technical disasters, malicious acts, or terrorist events, the impact of a pandemic is much more difficult to determine because of the difference in scale and duration [1]. It is difficult to predict how long school closures will last, so the health, food security, and nutrition of the most vulnerable children must be prioritised [27]. It could last for many weeks and months. It is likely that vaccines against the new virus will not be available for six to eight months following the emergence of the virus. Such impacts may continue after emergencies are over; therefore, it is essential to devise additional efforts to ensure that children with disabilities go back to school and are prioritised. Such settings require increased levels of risk mitigation and support to prevent COVID-19 transmission. Governments and their partners need to develop strategies and programmes to prepare for a pandemic.

\section{Research Results and Discussions On Pandemic}

The results of the interviews conducted are presented below. Two-point of discussion was the existence of a contingency plan and Pandemic coordinator in institutions serving PLWD. The research site comprised of two institutions serving for PLWD, a home for people with disabilities (HPWD) in Evaton and a public school for learners with special needs (LSEN) in Katlehong. The HPWD provides service to 10 users who reside in the facility throughout the year. The special school offers day-to-day service for 318 learners with special needs who commute to school daily.

\section{Existence of a Contingency Plan}

Institutions are required to adopt a planning approach for ensuring that critical operations and services can be maintained [1]. Institutions may run out of books, food due to unforeseen circumstances for their daily activities. This section aimed to inquire if the two institutions had a contingency plan and if it was updated continually. The study found that the home for 
PLWD did not have a disaster plan. The special school had a disaster plan, and it has been updated in January 2020. Every organisation must plan for the specific disruptions it may face during a disaster or pandemic. The overall goal of planning is to reduce illness (morbidity), death (mortality), and social disruption resulting from the pandemic. A pandemic plan is thus a living document that is reviewed at intervals and revised periodically. Plan updates are essential for other emergencies as well. Deliberation with the managers inquired about the other plans (health, cleaning, communications plan, and food security plan for the LSEN) that complement the contingency plan. Both institutions had health, cleaning, and communication plan.

\section{Health Plan}

During a pandemic, it is expected there will be a greater extent of illness and death than experienced during an ordinary season. The health plan is essential to facilitate incident occurring when users/learners get sick either when they visit the family or when the learner is sick when commuting to school. The school also has a nursing sister dedicated to the school. The school also has a sick room and the separate room for cooling high temperature observed as a COVID-19 requirement. The school also has general assistants who help with routine logistics and issuing of water in the designated areas. High mobility may promote the rapid spread of the virus. The HPWD informed that the facility limited the movement of the users from visiting the parents as they may be infected when using public transportation or from other family members. They also limited the number of visitors at the facilities level. However, arrangements are made for donors who wish to deliver clothes and food items.

\section{Cleaning Plan}

The cleaning plan was developed alongside COVID-19 regulations which espouse washing of hands, protection for PLWD and safety of staff and users. The interesting response from the LSEN indicated that a roster was developed for adhering to hygiene. Most schools employed COVID-19 Brigades and classroom assistance. It was also found that PLWD rely on assistive support from specialised support staff. Such staff also serve continually disinfect the surfaces in ensuring that hygiene compliance is maintained in the respective institutions. The HPWD comprise of assistants who work on a rotational basis (night and day shift) as the users need considerable care and support.

\section{Food Security Plan}

The disruption and closure of schools around the world have negatively impacted on children living in low-income households. Some learners might not have access to regular school feeding and nutrition services during the pandemic [27]. Making sure that PLWD is fully integrated into food security interventions is an essential part of achieving critical development goals [14]. It is difficult to predict how long school closures will last, so the health, food security and nutrition of the most vulnerable children must be prioritised. Social protection can also support income protection for those affected to bounce back from economic and healthrelated shocks. For this reason, 418 social protection schemes have already been adopted or expanded globally to respond to COVID-19 [25].

Institutions need to provide incentives to reduce mobility. In terms of health plan, LSEN school reorganised the food handling stations whereby three (3) break meal servings for the learners in order to avoid staggering in the eating room.

\section{Communication Plan}

Both institutions have a communication plan. The LSEN school had just developed a bulk short message services (SMS) system for communicating to the parents of the learners. A valid email address, the telephone is up and running. The telephone number of the school principal is accessible on the internet search. The HPWD also use SMS to send communication to parents and to their coordinator.

\section{Pandemic Coordinator and Pandemic Coordinator}

The profound uncertainty about the virus and its trajectory, and about how other countries will respond, only magnifies the importance of leadership [28]. This section asked if the school/centre has a dedicated coordinator or team and for disasters or pandemics. It was found that both institutions had a responsible person to deal with incidences. Each institution comprises of a school governing board that serves as an oversight role for all activities conducted. A followup question aimed to understand the responsibilities of the coordinator and the team. The government is the natural leader for overall coordination and communication efforts. A coordinator is responsible for developing and regularly reviewing the contingency plan for the institution. The officer also identifies core business-essential functions in the institution. And serve as a liaison point among all functionaries of the 
organisation, including external bodies. The officer also disseminates information and advice on the scope of any incident. The officer also coordinates and assist in the distribution of personal protective equipment (PPE) to staff and users of the service. This was evident in the schools where learners were issued with PPEs. With the current state, the coordinator role is so crucial in ensuring that all staff and service users are protected.

\section{DISCUSSIONS AND ONSIDERATIONS FOR PLWD}

This section responds to the research objective on which additional considerations are needed for people with disability during the COVID-19 outbreak. Since January 4 2020, the WHO has shared information about the outbreak, providing technical advice and guidance for containing the virus [28]. Generally, any pandemic hits hard to the nation, and COVID-19 presents a significant and unprecedented challenge for many people with disability. There's already a dramatic gap in achievement and outcomes between students with disabilities and those without disabilities. Such cases also have an impact on educators as they will struggle to help LSEN to make up for this lost time. This impact can be mitigated if simple actions and protective measures are taken by key stakeholders [12]. It is recommended that families must be put a plan in place to ensure the continuation of the care and support you need. Households must also prepare for the instance should they contract COVID-19. Supporting a disabled family member is strenuous; therefore, the mental and physical health of household members and caregivers should be supported. The World Health Organisation recommends the following for mitigating possible interruptions for institutions serving PLWD:

\section{Actions for Governments}

- Ensure public health information and communication is accessible

- Undertake targeted measures for people with disability and their support networks

- Undertake targeted measures for disability service providers

\section{Actions for Health-Care Workers}

- Ensure COVID-19 health care is Accessible, Affordable and Inclusive

- Deliver telehealth for people with disability

\section{Actions for Disability Service Providers}

- Develop and implement service continuity plans

- Communicate frequently with people with disability who have complex needs and their support networks

- $\quad$ Reduce potential exposure to COVID-19 during provision of disability services

\section{Actions for the Community}

- Basic protection measures to be adopted by the general public

- $\quad$ Flexible work arrangements and infection control measures to be supported by employers

- Increased access to stores to be provided by store owners for vulnerable populations

- $\quad$ Extra support to be provided by family, friends and neighbours for a person with disability [12].

COVID-19 crisis should also sharpen our thinking about climate change, reinforcing the fact that early intervention is vastly more effective and less costly than waiting until the crisis hits [7]. Planning for a possible pandemic continues to evolve and is ongoing. In fact, emergency planning is never "written in stone" rather, it provides a context for more efficient problemsolving at the time of an emergency. Literature review for this study proves that institutions serving PLWD has done considerable work to prepare for public health emergencies. Many of these measures have been declared as short-term, although economic support measures are likely to have a longer life than those impacting social gatherings [7]. The post-COVID world will be shaped by decisions being made in the crucible of the fight against the virus [28]. The roadmap also demands buy-in from governments and parliaments, from social partners and citizens [31]. Lots of countries have done good things. Uganda, for example, has enshrined disability rights in its constitution, and people with disabilities participate at every level of the political process. Vietnam and Laos get top marks for a project to make schools inclusive, while Yemen deserves applause for its support services [31].

One of the identified impacts related to PLWD during the pandemic was stigmatising students and staff who may have been exposed to the virus. It is important for Education settings should continue to be welcoming, respectful, inclusive, and supportive 
environments to all. Adequate measures taken by schools can prevent the spread of the virus while minimising disruption and protecting students and staff from discrimination.

\section{Food Security and Schools Closure}

The possibility of school closure is a key reason for engaging in business and educational continuity planning. A pandemic expects institutions to maintain flexibility and responsiveness to changing conditions for supply and distribution of food. Provision of nutrition services is essential to ensure compliance with COVID19 protocols. Usage of available resources to safeguard schoolchildren's food security and nutrition should be prioritised. Institutions must build upon existing safety-net structures to cover vulnerable schoolchildren. In terms of safety-net, the South African government is no exception to this. In April 2020 the social grants pay-out was increased to R250 (14.28 USD) for a period of five months. Previously, social grants pay-out were received in two separate days (on the $1^{\text {st }}$ and $7^{\text {th }}$ of every month). Old age grant pay-out is now issued on a different day to adhere to social distancing. Food and nutrition needs of vulnerable schoolchildren must be considered when designing any large-scale national response to COVID-19. The South African government also ensured that the school nutrition programme is implemented during school closure. It is important for government authorities dealing with school feeding to consider a plan for when reopening occurs.

\section{Where Schools Remain Open}

Dealing with a pandemic is a daunting task when institutions must deal with the provision of service and food security. Adequate nutrition is essential for schoolchildren's health and wellbeing. Many of the children rely heavily on such programmes. In order to support schoolchildren during this critical time, any new design should ensure that the food security and nutrition needs of this age group are addressed, considering baseline food security and malnutrition situation, gender issues, social norms influencing food behaviours and socioeconomic vulnerabilities. Institutions may determine what planning and responsibility model works best. The WFP suggest that the facilities for PWD should:

- Promote optimal water, sanitation and hygiene services and ensure optimal hygiene and regulation of food vendors;
- Ensure and continue the provision of essential school health and nutrition package (school feeding, micronutrient supplementation, deworming, malaria prevention and oral hygiene);

- Avoid potential deterioration in food safety standards;

- $\quad$ Ensure adequate nutrition content of meals; and

- $\quad$ Create contingency plans for the distribution of meals/food baskets in preparation for potential rapid closure of schools benchmarks [27].

Lessons learnt from other epidemics such as the Ebola outbreak, point to the efficacy of interventions such as the reallocation of food from the school feeding programme to the overall emergency response. This aimed to address the entire vulnerable households of children living in Ebola-affected households and Ebolaorphans living in hosting families. During the Ebola outbreak, all children attending the selected schools were targeted, and as such school feeding helped communities overcome stigmatisation and rebuild trust towards agencies and authorities:

- In Costa Rica, initially, the government decided to keep school canteens open amid school closures but later decided to set up collection points for distributing food baskets to families. Such food baskets included perishables and fresh foods sourced from smallholder farmers;

- In Colombia, the ministry of education gave autonomy to the regions to make decisions on school feeding responses according to their capacities and needs;

- In Kerala, India, teachers have been communicating with families to collect or distribute food baskets in their localities; and

- In the United Kingdom, the government has released preliminary guidance for vulnerable schoolchildren, promoting various approaches ranging from providing families with supermarket vouchers to maintaining some school canteens open for children of families working in health, police and delivery services [27].

Community-based organisations established for community feeding schemes existed before COVID-19, and the support from respective schemes continued to 
help the elderly and children in various jurisdiction of South Africa. Long queues were observed during this time while some were hampered by corruption and greed by non-deserving residents who have stable employment and source of income.

\section{CONCLUSION}

This paper has summarised a review of literature on the effects of COVID-19 pandemic on people with disabilities and the role of pandemic planning. Measures are being taken to increase our capacity to respond to the threat of a pandemic. Pandemic occurrence serves as an opportunity to re-think how emergency planning can be inclusive of children with disabilities. The discussion above provides evidence that a pandemic can easily overwhelm the health care system throughout the nation. A pandemic outbreak could also jeopardise essential community services by causing high levels of absenteeism in critical positions in every workforce. The success of pandemic planning and preparedness efforts depends on what we all put into the process. Diligent planning was found to be essential. Parts of a pandemic plan can be effective during many other local community crises. It can also improve the local government's ability to manage other operational risks associated with supply chains and transportation disruptions. The empirical survey also informs that institutions for PLWD have a responsibility and evidence was proven during the surveys. The two institutions had contingency plans for dealing with COVID-19 preparedness.

\section{RECOMMENDATIONS}

During this uncertain time, family-school collaboration is essential than ever. A coordinated community effort is needed to keep licensed child care facilities open during a pandemic. In addition, blueprints for a COVID-19 pandemic preparedness plan can easily be used for broader contingency plans [9]. So far, mainstream responses for continued learning during the COVID-19 crisis have focused on strategies and solutions deployed during previous emergencies [32]. Effective implementation of the plan compels institutions to set targets or define progress indicators that can be used to measure progress. A pandemic plan should be dynamic and must be known by all stakeholders who could use it for unforeseen circumstances. The needs and specificities of urban and rural populations, in particular, vulnerable subgroups need to be considered when designing contingency measures. The Food and Agriculture
Organization of the United Nations (FAO) has a specific role to play in this response. Pandemic preparedness process must take account of the social protection systems and ensure the resilience of food systems to ensure the resilience of food systems [25].

\section{Communication}

Meaningful and clear communication and collaboration between parents and schools can go a long way toward solving problems. Provision of a hotline in multiple formats (e.g. telephone, email, SMS, easy language apps, etc.) for people with disability to ask questions and raise concerns must be contemplated.

\section{Review of Plans}

The empirical survey indicated that institutions lack to review their plans. The World Health Organization recommended essential checklist for managing pandemic preparedness. Therefore, organisations have to review and document all activities needed to keep the child care facility open and functional in a safe and acceptable manner. This can only be achieved if the plan is tested and revised regularly.

\section{Additional Support and Care}

Children with disabilities require physical therapy, related care services. Children with learning disabilities are sensitive to changes in routine and need teacher support to work independently [32]. Institutions should ensure continuity of services and support in case the number of available caregivers may be reduced. In this regard, fast-track training opportunities for new workforce must be considered. They must also ensure service providers and caregivers for people with disability have access to personal protective equipment and COVID-19 testing free of charge [11].

\section{Access to the Internet}

Limited internet access hinders the learning environment. About $43 \%$ of learners globally do not have household internet or unaffordable mobile data plans [32]. PLWD consistently have low rates of media access (with the exception of radio). The dawn of load shedding also has an impact on low-income households who do not have means for alternative energy device. McClain-Nhlapo [32] suggested that the provision of quality paper-based documents should not be underestimated as they continue to be low-cost, low-tech solutions for continued information sharing. 
Paper-based material is essential to adhere to social inclusion model. Paper-based material can be used for social protection application.

All preparedness and response plans must be inclusive of and accessible to women with disabilities. PLWD can be asked on how they would like information to be presented [20]. Engaging PLWD and their representatives in planning the pandemic response is essential. Health services should be prioritised with access to health information to people with all forms of disabilities.

\section{REFERENCES}

[1] Leonovic P. Pandemic Preparedness for Financial Institutional. Washington, DC: International Monetary Fund, 2020.

[2] Piatta F. Rights in Action, Good practices for Inclusive Local Governance in West Africa, Benin, Burkina Faso, Mali, Niger, Senegal. Sierra Leone, Togo, Handicap International 2010.

[3] Quarmby CA, Pillay M. The intersection of disability and food security: Perspectives of health and humanitarian aid workers. African Journal of Disability (Online). 2018; 7: 1-9. https://doi.org/10.4102/ajod.v7i0.322

[4] Hiranandani VS. Disability, poverty and food sovereignty: Advancing the human security and development agenda. Review of Disability Studies: International Journal. 2009: 73-84.

[5] Jarus O. 20 of the worst epidemics and pandemics in history. LiveScience, 2020. March, 21.

[6] Gartner Research. The Pillars of Pandemic Planning. Gartner, Inc. (NYSE: IT) 2020. https://www.gartner.com/en/ documents/3980329/the-pillars-of-pandemic-planning

[7] Bishop J, Roberts A. Geopolitics: Resilient and Sustainable Globalisation. In the World Economic Forum. 2020. Challenges and Opportunities in the Post-COVID-19 World. Cologny/Geneva, Switzerland: World Economic Forum, 2020.

[8] Hickok K. How Does the COVID-19 Pandemic Compare to the Last Pandemic?. LiveScience 2020. https://www. livescience. com/covid-19-pandemic-vs-swine-flu. html. 2020.

[9] World Health Organization (WHO). WHO checklist for influenza pandemic preparedness planning (WHO/CDS/ CSR/GIP/2005.4). World Health Organization, 2005.

[10] World Economic Forum. Challenges and Opportunities in the Post-COVID-19 World. Cologny/Geneva, Switzerland: World Economic Forum, 2020.

[11] Deb P, Furceri D, Ostry JD, Tawk N. The effect of containment measures on the COVID-19 pandemic 2020. https://doi.org/10.5089/9781513550268.001

[12] World Health Organization (WHO). Protecting people with disability during the COVID-19 pandemic (WHO-EM/HLP/122/E). World Health Organization, 2020.

[13] United Nations Development Programme (UNDP). Disability Inclusive Development in UNDP. New York, USA: UNDP 2018.

[14] Stloukal L. Disability and Food Security: An Unfinished Policy Agenda 2018. http://www.internationaldisabilityalliance.org/ faofood-insecurity
[15]

United Nations Development Programme. Disability-inclusive development. New York, USA: UNDP 2020.

[16] Elwan A. Poverty and Disability A Survey of the Literature: Social Protection Unit. Human Development Network, The World Bank, 1999 Dec.

[17] FAO. An Introduction to the Basic Concepts of Food Security. EC - FAO Food Security Programme 2008. www.foodsec.org

[18] Manitoba Education, Citizenship and Youth. Preparedness Guidelines for Manitoba School Divisions and Schools (K - 12). Dublin 2007.

[19] Manitoba's Public Health. Preparing for Pandemic Influenza in Manitoba: A Guide for the public from the Office of the Chief Medical Officer of Health 2006.

[20] Seattle-King County. An Influenza Pandemic Planning Guide for Homeless and Housing Service Providers. Washington: SeattleKing County, 2006.

[21] Edge J. Working in development: Put disability on the food security agenda 2013; http://www.theguardian.com/globaldevelopment-professionals-network/2013/

[22] Meaney-Davis J, Lee H, Corby N. The impacts of COVID-19 on people with disabilities (No. 35) London, UK: Disability Inclusion Helpdesk 2020.

[23] Rohwerder B. Disability stigma in developing countries 2018 https://www.ids.ac.uk/publications/disability-stigma-in-developingcountries/

[24] Commonwealth of Australia. Management and operational plan for people with Disability Australian Health Sector Emergency Response Plan for Novel Coronavirus (COVID-19). Canberra: Commonwealth of Australia 2020.

[25] FAO. Social Protection and COVID-19 response in rural areas. Rome: FAO, 2020. https://doi.org/10.4060/ca8561en

[26] International Disability Alliance (IDA). The story of Fahad: a man with a physical disability unable to access personal assistance services 2020. www.internationaldisabilityalliance. org

[27] WFP F, UNICEF. Interim guidance note: Mitigating the effects of the COVID-19 pandemic on food and nutrition of schoolchildren. Rome, Italy: World Food Programme, Food and Agriculture Organization of the United Nations 2020.

[28] Woods N. Global Governance: Planning for the World After COVID-19. Cologny/Geneva, Switzerland: World Economic Forum, 2020.

[29] European Centre for Disease Prevention and Control. Why is pandemic preparedness planning important? European Centre for Disease Prevention and Control 2020. www.ecdc.europa.eu

[30] Alter R. Regional Governance: An Opportunity for Regional Organisations? In World Economic Forum. 2020. Challenges and Opportunities in the Post-COVID-19 World. Cologny/Geneva, Switzerland: World Economic Forum, 2020.

[31] Adams L, Guy M, and Last U. Making it Work: Good practices for disability-inclusive development and humanitarian action. France: A Handicap International Publication; 2015.

[32] McClain-Nhlapo C. An inclusive response to COVID-19: Education for children with disabilities. Global Partnership for Education 2020. https://www.globalpartnership.org/blog/ inclusive-response-covid-19-education-childrendisabilities

https://doi.org/10.6000/2292-2598.2021.09.01.2

(C) 2021 Loraine Boitumelo (LB) Mzini; Licensee Lifescience Global.

This is an open access article licensed under the terms of the Creative Commons Attribution Non-Commercial License (http://creativecommons.org/licenses/by-nc/3.0/) which permits unrestricted, non-commercial use, distribution and reproduction in any medium, provided the work is properly cited. 